This item was submitted to Loughborough's Research Repository by the author.

Items in Figshare are protected by copyright, with all rights reserved, unless otherwise indicated.

\title{
Analysis of forces in vibro-impact and hot vibro-impact turning of advanced alloys
}

PLEASE CITE THE PUBLISHED VERSION

http://www.ttp.net/1660-9336.html

PUBLISHER

(c) Trans Tech Publications Inc.

VERSION

AM (Accepted Manuscript)

LICENCE

CC BY-NC-ND 4.0

\section{REPOSITORY RECORD}

Muhammad, Riaz, Agostino Maurotto, Anish Roy, and Vadim V. Silberschmidt. 2019. "Analysis of Forces in Vibro-impact and Hot Vibro-impact Turning of Advanced Alloys". figshare. https://hdl.handle.net/2134/8729. 
This item was submitted to Loughborough's Institutional Repository (https://dspace.lboro.ac.uk/) by the author and is made available under the following Creative Commons Licence conditions.

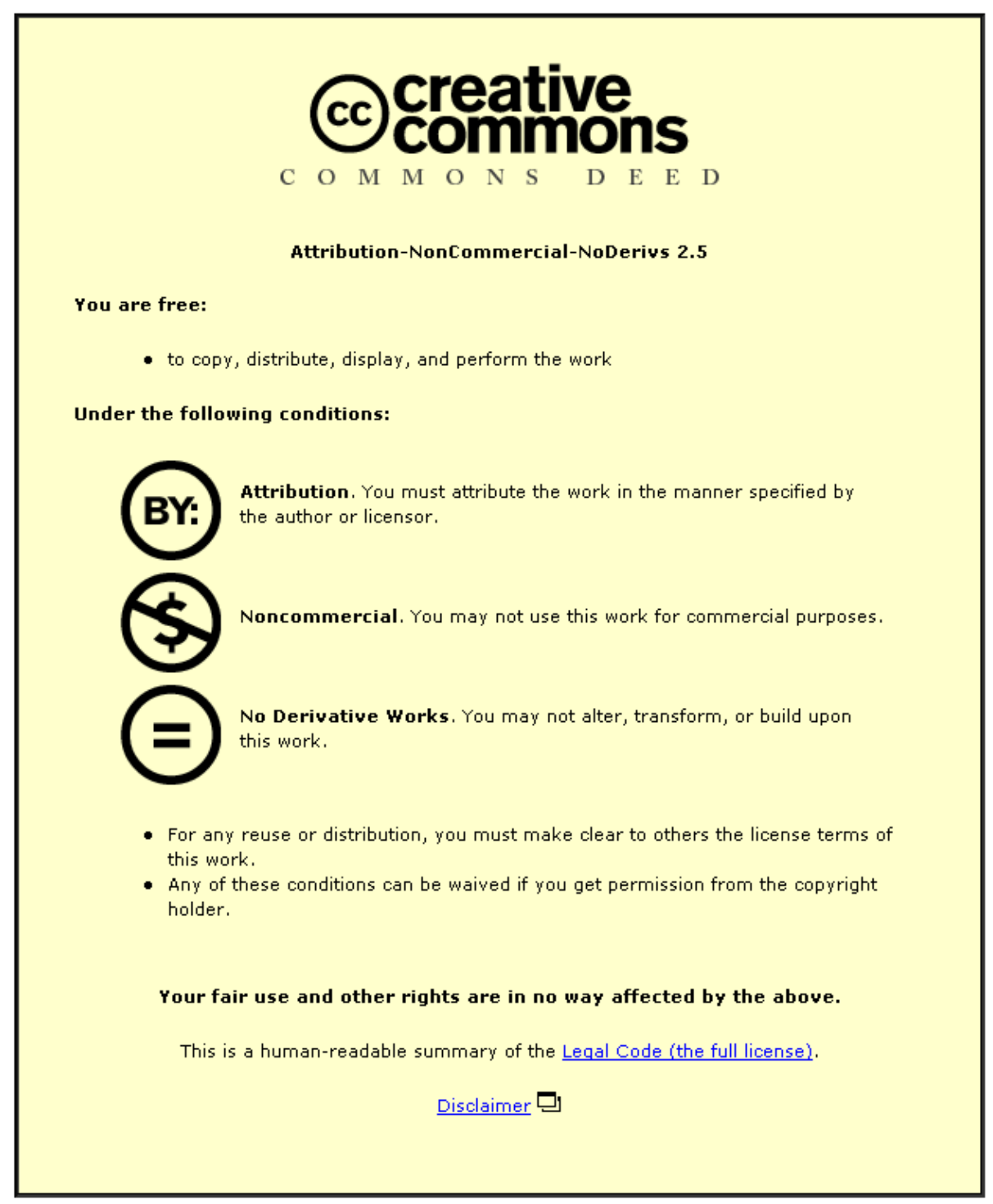

For the full text of this licence, please go to: http://creativecommons.org/licenses/by-nc-nd/2.5/ 


\title{
Analysis of forces in vibro-impact and hot vibro-impact turning of advanced alloys
}

\author{
R. Muhammad ${ }^{\mathrm{a} *}$, A. Maurotto ${ }^{\mathrm{b}}$, A. Roy $^{\mathrm{c}}$ and V V. Silberschmidt ${ }^{\mathrm{d}}$ \\ Wolfson School of Mechanical and Manufacturing Engineering, Loughborough University \\ Loughborough, Leicestershire, UK \\ a*R.Muhammad@lboro.ac.uk, ${ }^{\mathrm{b}}$ a.maurotto@lboro.ac.uk, ${ }^{\mathrm{c} A . R o y 3 @ l b o r o . a c . u k},{ }^{\mathrm{d}}$ V.Silberschmidt@lboro.ac.uk
}

\section{Abstract}

Analysis of the cutting process in machining of advanced alloys, which are typically difficultto-machine materials, is a challenge that needs to be addressed. In a machining operation, cutting forces causes severe deformations in the proximity of the cutting edge, producing high stresses, strain, strain-rates and temperatures in the work-piece that ultimately affect the quality of the machined surface.

In the present work, cutting forces generated in a vibro-impact and hot vibro-impact machining process of Ti-based alloy, using an in-house Ultrasonically Assisted Turning (UAT) setup, are studied.

A three-dimensional, thermo-mechanically coupled, finite element model was developed to study the thermal and mechanical processes in the cutting zone for the various machining processes. Several advantages of ultrasonically assisted turning and hot ultrasonically assisted turning are demonstrated when compared to conventional turning.

Keywords: cutting forces, Ti-alloy, finite element, ultrasonically assisted turning (UAT), HUAT.

\section{Introduction}

Titanium alloys offer an enormous application potential within extreme operating conditions in several industrially relevant areas. However, the main hindrance in the manufacture of components made of these alloys in modern industries is that Ti-alloys are graded as hard-tocut materials, making them difficult to machine using conventional techniques. One of the commonly used machining operations is turning where a single point cutting tool fixed to a tool post, moves against a revolving workpiece removing material to achieve a desired shape of a component. Conventional turning (CT) of Ti-alloys produces high cutting forces which ultimately results in pre-mature tool failure and lack of dimensional accuracy in the finished workpiece. In recent decades, several researchers have contributed to improvements in turning of modern alloys by using high-speed machining techniques to address the well documented deficiencies of CT [1].

Ultrasonically assisted turning (UAT) is an advance machining technique, in which up to 30000 low energy vibro-impacts are superimposed on the cutting tool. This technique offers significant improvement in the processing of modern alloys [2, 3]. Compared to CT, this technique results in multi-fold decrease in cutting forces with a concomitant improvement in surface finish of the machined workpiece [3, 4]. In any machining operation reduction of cutting forces can increase the tool life and reduce residual stresses in the machined workpiece [5].

In order to increase the metal removal rate and to further reduce the cutting forces, hot machining techniques are used. Depending on the temperature sensitive material properties of the workpiece, the material to be machined is heated up-to a certain temperature using a band resistance heater. Typically, the yield strength of a material reduces with an increase of temperature, thus, reducing the cutting forces required to cut the materials. Advantages of UAT when compared to CT and hot ultrasonically assisted turning (HUAT) when compared to UAT on Ti-alloys are studied by a series of experiments conducted on the in-house UAT setup at Loughborough University.

A 3D finite element (FE) model of ultrasonically assisted and hot ultrasonically assisted cutting is developed to study the effects of various machining parameters and the effect of 
pre-heating of the workpiece on the cutting forces as well as to suggest the optimum cutting conditions for the processing of modern Ti-alloys.

\section{Experimental setup and results}

The experimental setup consists of a modified Harrison 300 lathe, a custom-built ultrasonic coupled transducer mounted on a wave-guide, a force measurement system, a band resistance heater, a temperature measurement system, data acquisition, system charge amplifier and A/D converter.

The cutting force components were measured with a Kistler piezoelectric dynamometer (KIAG SWISS Type 9257A), mounted on the cross slide of the lathe by a custom built tool post. The ultrasonic transducer is mounted on the dynamometer (Fig 1(a)) with adequate insulation to shield out the heavy electrical disturbances which are generated during machining operations. A band resistance heater (DYN-5234) used to heat up the workpiece to the required temperature $\left(200^{\circ} \mathrm{C} \pm 20^{\circ} \mathrm{C}\right)$ is mounted encapsulating the workpiece. Calibrated $\mathrm{K}$-type thermocouples were used to measure the temperature of the workpiece surface during the heating process. Additionally, a micrometric dial gauge is used to ensure an accurate depth of cut. Figure 1 (a) shows the schematic diagram of the experimental setup.

The following cutting condition was used in the test: Cutting speed $V_{C}=10 \mathrm{~m} / \mathrm{min}$, Dept of cut $a_{p}=0.3 \mathrm{~mm}$ and feed rate $t_{1}=0.1 \mathrm{~mm} / \mathrm{rev}$. An ingot of the Ti alloy (Ti15V3Cr3Al3Sn) is used as a work-piece material and a commercial tungsten carbide insert, PVD coated with TiN, (DNMG-150608 supplied by Seco) is used as a cutting tool. All experiments were carried out in dry cutting condition without any lubricant and tangential component of force which is the main cutting force in machining is measured in the experimentation. Several tests for CT, UAT and HUAT were carried out and the cutting force in the cutting direction was measured. The cutting force reduce significantly during ultrasonically assisted operations as compared to CT. Comparison of the experimentally measured values (Figure 1 (b)) shows that the tangential component of the cutting force decreases from $102 \mathrm{~N}$ to $32 \mathrm{~N}$ (reduction of 69\%) after the ultrasonic vibration are superimposed to the cutting tool. Similarly, HUAT caused a reduction of $19 \%$ (from $32 \mathrm{~N}$ to $26 \mathrm{~N}$ ) in forces as compared to UAT. In general, (H)UAT offers substantial benefits when compared to CT, in particular, reduction in the chatter noise during operations, better surface finish and significant force reduction.

\section{Finite element model description}

A 3D fully thermo-mechanically coupled implicit finite element model is implemented in the commercially available finite element software, MSC MARC/MENTAT [6]. The model is based on an updated Lagrangian procedure that provides a transient analysis for an elastoplastic material and accounts for the frictional contact interaction between the tool and the workpiece.

\subsection{Model geometry and kinematics}

The initial mesh, dimension and relative movement of the workpiece together with the cutting tool of orthogonal turning process is shown in Figure 2. In orthogonal cutting the tool edge is normal to cutting and feed direction. In the FE simulation of Ti-alloy, a deformable workpiece with dimension of $3.0 \mathrm{~mm}$ in length and $0.7 \mathrm{~mm}$ in height is used. Four-noded tetrahedral elements with a minimum length of $0.05 \mathrm{~mm}$ were used to mesh the workpiece. A rigid cutting tool with a tungsten carbide coating moving at a speed of $V_{C}=10 \mathrm{~m} / \mathrm{min}$ is modelled in the FE simulation. Harmonic oscillation of amplitude $a=0.03 \mu \mathrm{m}$ and frequency $f=20 \mathrm{kHz}$ is then superimposed on the cutting tool in the tangential direction in order to model ultrasonic vibration of the tool. The material properties defined for the cutting tool were those of tungsten carbide that was discretized into eight-noded, 500 iso-parametric, irregular quadrilateral elements with approximately 402 nodes. The ambient temperature is selected as $20^{\circ} \mathrm{C}$ for the cutting tool and workpiece in normal cutting condition and for 
HUAT a temperature of $200^{\circ} \mathrm{C}$ is applied on the workpiece elements. The number of simulation steps is kept at 1500 with a total time of 0.024 sec.
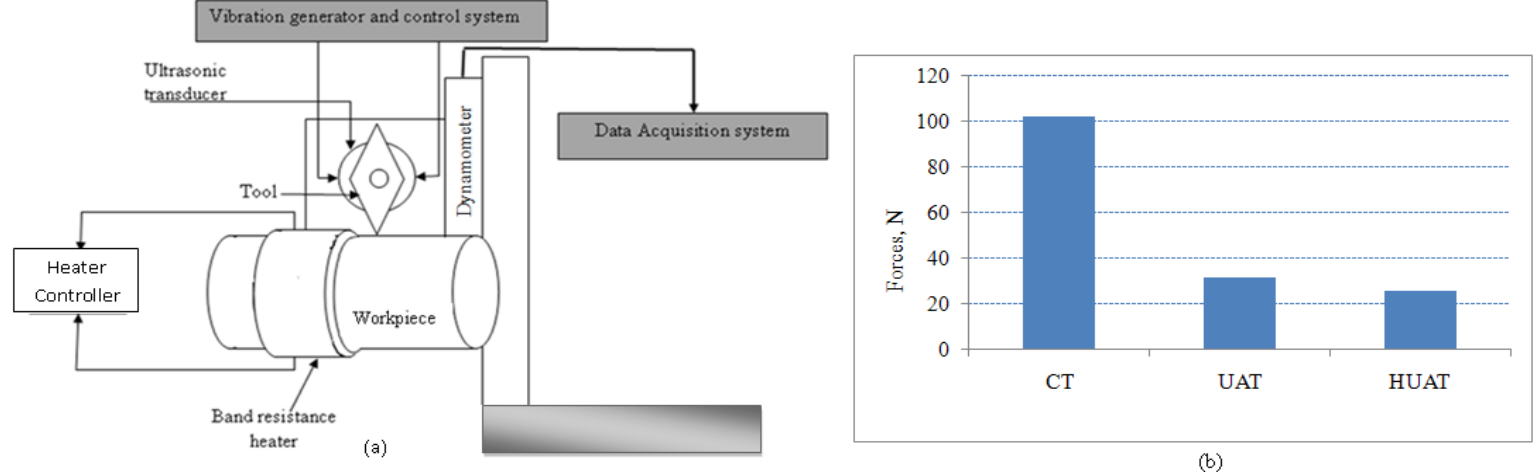

Figure 1: (a) A schematic diagram of experimental setup, (b) Comparison of forces in cutting direction for CT, UAT and HUAT $\left(a_{p}=0.3 \mathrm{~mm}, V_{c}=10 \mathrm{~m} / \mathrm{min}, t_{1}=0.1 \mathrm{~mm}, f=20 \mathrm{kHz}\right.$ and

$$
a=30 \mu \mathrm{m})
$$

\subsection{Material model}

In order to obtain a stress-strain behaviour of the Ti-alloy (Ti15V3Cr3Al3Sn) under various strain rates and temperatures, a split-Hopkinson test [7] was carried out at Tampere University of Technology, Finland. The material response of the alloy for different strain rates at room temperature obtained in the test is shown in Figure 3 (a). The nonlinear strainrate and temperature-sensitive material model used in our numerical simulations comprised of twelve different stress-strain curves obtained for a combination of four different strain rates $\left(0.1 \mathrm{~s}^{-1}, 1 \mathrm{~s}^{-1}, 3331 \mathrm{~s}^{-1}, 10^{10} \mathrm{~s}^{-1}\right)$ one and three different temperature values $\left(20^{\circ} \mathrm{C}\right.$, $600^{\circ} \mathrm{C}, 800^{\circ} \mathrm{C}$ ). The stress-strain response for a strain rate of $10^{10} \mathrm{~s}^{-1}$ is estimated to be $20 \%$ higher than the mechanical response for a strain rate of $3331 \mathrm{~s}^{-1}$.

These curves were modified in such a way that the magnitudes of stress for high strain levels are limited by the ultimate dynamic tensile stress (UTS) (Figure 3 (b)). The elastic material properties of the Ti-alloy are $E=87 \mathrm{GPa}, v=0.3, \rho=4900 \mathrm{~kg} / \mathrm{m}^{3}$, where $E, v$ and $\rho$ are the Young's modulus, Poisson's ratio and density of the material, respectively. Thermal conductivity of the Ti-alloy is $k=8.08 \mathrm{~W} / \mathrm{mK}$. A temperature-dependant thermal expansion and specific heat $\left(C_{p}\right)$ behaviour of the material was incorporated into the model. The details are available elsewhere [8].

\subsection{Friction Model}

Various friction models are available to model the interaction of tool-chip-workpiece interface [9-11]. A modified shear friction model is believed to best represent the friction behavior [6].

$\sigma_{f r} \leq-m_{f r} \frac{\bar{\sigma}}{\sqrt{3}} \frac{2}{\pi} \operatorname{sgn}\left(\mathrm{V}_{\mathrm{r}}\right) \operatorname{artan}\left(\frac{V_{r}}{V_{\mathrm{cr}}}\right)$

Where $\sigma_{f r}$ is a friction stress, $\bar{\sigma}$ is the equivalent stress, $V_{r}$ is the relative sliding velocity, $V_{\text {cr }}$ is the critical sliding velocity below which sticking is simulated, $m_{f r}$ is the friction coefficient and $\operatorname{sgn}(\mathrm{x})$ is the signum function.

\section{Results and discussion}

The FE simulations for the studied Ti-alloy were carried out and the results for UAT, HUAT and CT are presented and discussed in this section. For all the simulations the cutting parameters are similar to the ones discussed in section 2. Effect of varying amplitude and frequency of ultrasonic vibration on cutting forces are also investigated. 


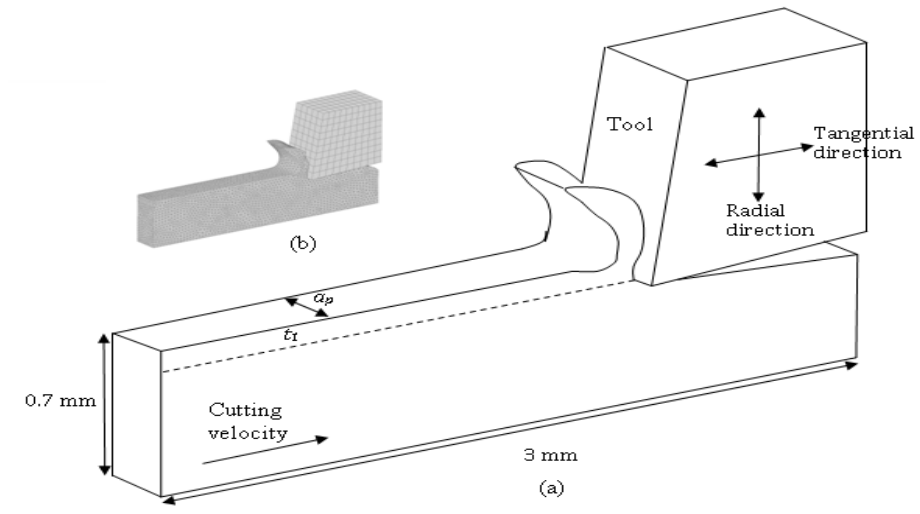

Figure 2: (a) A scheme of relative movement of the cutting tool and workpiece (b) and fully formed chip with re-meshed body

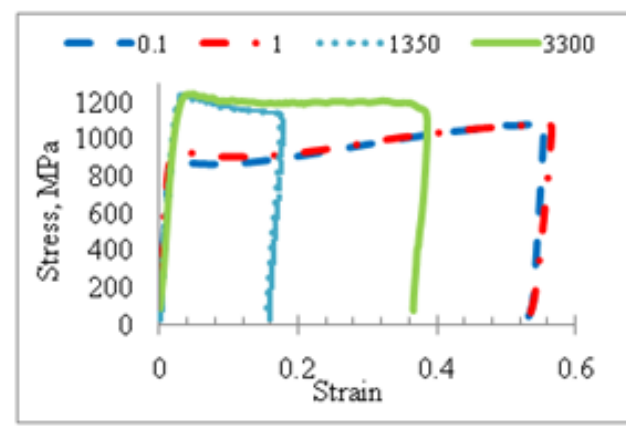

(a)

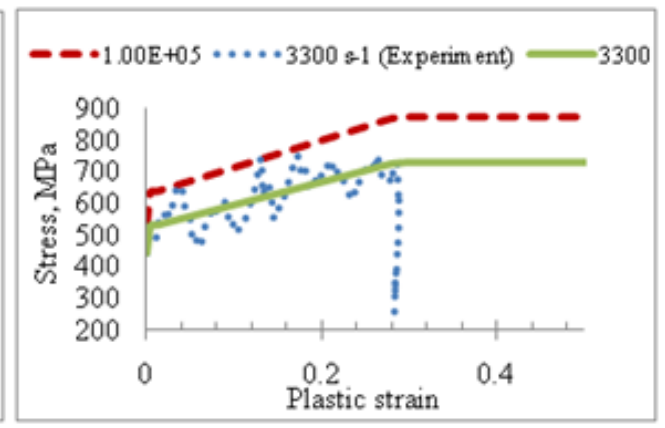

(b)

Figure 3: (a) Stress-strain diagram of Ti15V3Cr3Al3Sn obtained from Split-Hopkinson test for different strain rates at room temperature (b) Modified strain-rate-sensitive material model for $600^{\circ} \mathrm{C}$

Application of ultrasonic vibration to the cutting tool and heating of the workpiece in turning of the Ti-alloy brought noticeable amount of reduction in the cutting forces. In CT the cutting tool is in continuous interaction with the workpiece, thus, a constant force level is observed after the initial stage of the tool engagement and chip formation. In UAT the vibrating tool causes the forces to fluctuate over a wide range (from zero to a peak CT force). Hence, only the average values of cutting forces are used for comparison. Figure 4 shows the cutting force in the cutting direction for CT, UAT and HUAT. Reductions of $70 \%$ (99 $\mathrm{N}$ to $30 \mathrm{~N}$ ) in tangential forces were observed in UAT when compared to CT. Similarly, cutting forces in HUAT are $19 \%$ lower than that of in UAT ( $25 \mathrm{~N}$ as compared to $30 \mathrm{~N}$ ). These results are in good agreement with our experimental measurement.

It is well known that the selection of appropriate vibration parameter such as amplitude and frequency of vibration is critical for UAT. This was investigated by means of FE analysis of UAT and HUAT. A reduction in cutting forces was observed with the increase in vibration amplitude for the same frequency. When the amplitude decreases from $30 \mu \mathrm{m}$ to $15 \mu \mathrm{m}$ the cutting forces increases $40 \%$ (from $30 \mathrm{~N}$ to $42 \mathrm{~N}$ ) and $41 \%$ (from $24 \mathrm{~N}$ to $34 \mathrm{~N}$ ) in UAT and HUAT respectively. Similarly, a further rise of 59\% (from $42 \mathrm{~N}$ to $67 \mathrm{~N}$ ) and $61 \%$ (from $34 \mathrm{~N}$ to $55 \mathrm{~N}$ ) was recorded in UAT and HUAT respectively as the amplitude was decreased from $15 \mu \mathrm{m}$ to $7 \mu \mathrm{m}$ (Figure 5 ).

Three frequencies (10 kHz, $20 \mathrm{kHz}$ and $30 \mathrm{kHz}$ ) were used to analyse the forces in the FE simulations of UAT and HUAT. An average $110 \%$ (from $30 \mathrm{~N}$ to $63 \mathrm{~N}$ ) increase in cutting forces was observed when the frequency in UAT is decreased from $20 \mathrm{kHz}$ to $10 \mathrm{kHz}$ for the same amplitude. A reduction of $2 \%$ (from $30 \mathrm{~N}$ to $29 \mathrm{~N}$ ) in cutting forces was recorded when the frequency was increased from $20 \mathrm{kHz}$ to $30 \mathrm{kHz}$ (Figure 6a). Similarly, a rise of 92\% 
(from $25 \mathrm{~N}$ to $48 \mathrm{~N}$ ) is recorded when vibration frequency is decreased from $20 \mathrm{kHz}$ to 10 $\mathrm{kHz}$ and a marginal decline of $2 \mathrm{~N}(8 \%)$ in cutting forces is observed with the increase of vibration frequency form $20 \mathrm{kHz}$ to $30 \mathrm{kHz}$ in HUAT (Figure 6b).

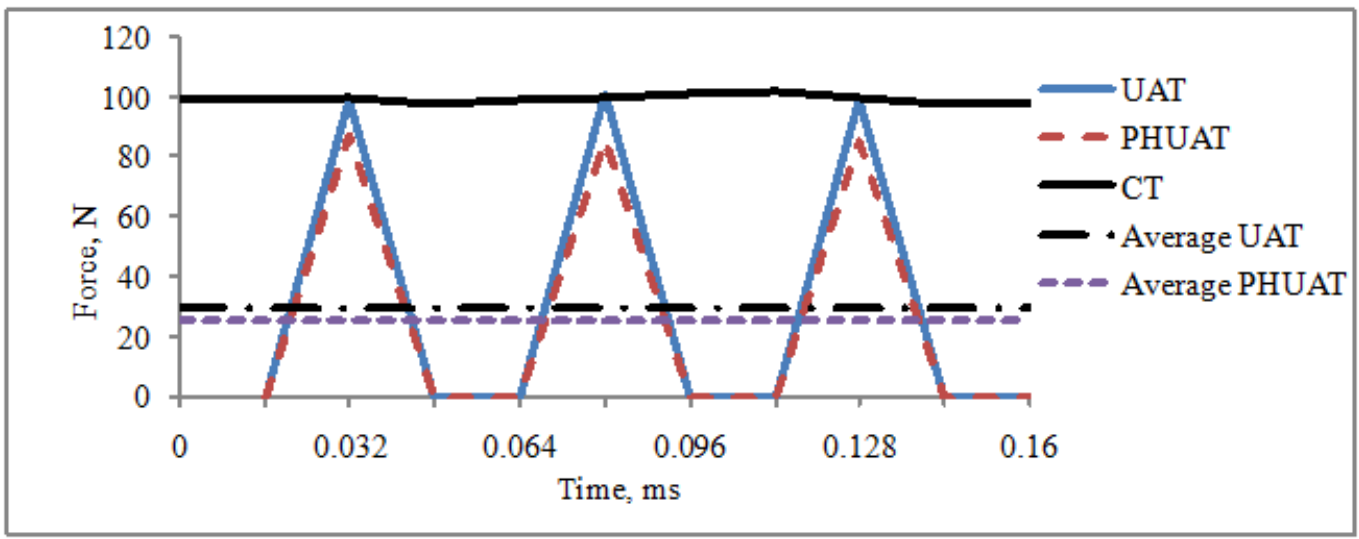

Figure 4: Comparisons of cutting forces on tool in the cutting direction for CT, UAT and HUAT simulation $\left(a_{p}=0.3 \mathrm{~mm}, V_{c}=10 \mathrm{~m} / \mathrm{min}, t_{1}=0.1 \mathrm{~mm}, f=20 \mathrm{kHz}\right.$ and $\left.a=30 \mu \mathrm{m}\right)$

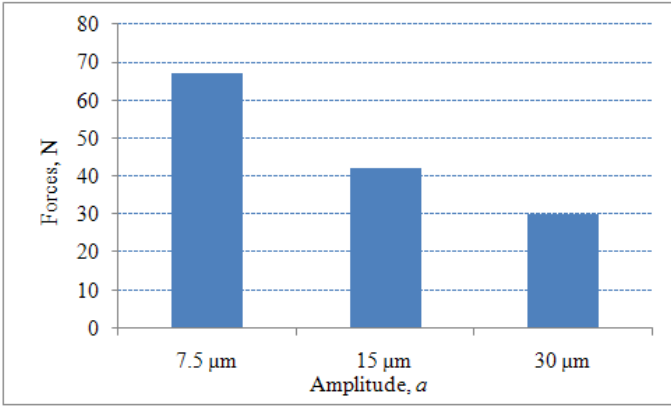

(a)

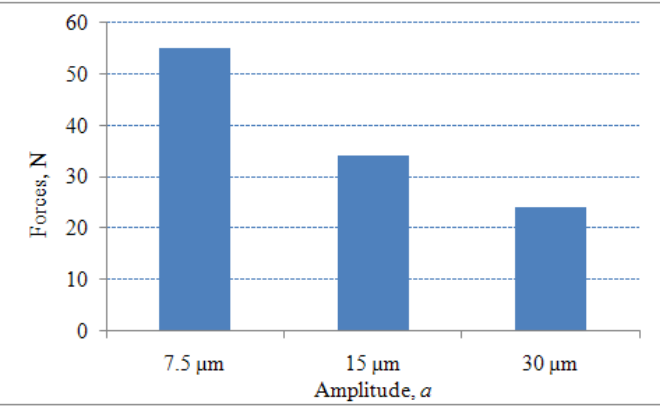

(b)

Figure 5: Effect of vibration amplitude on average cutting forces (a) in UAT (b) in HUAT $(f=20 \mathrm{kHz})$

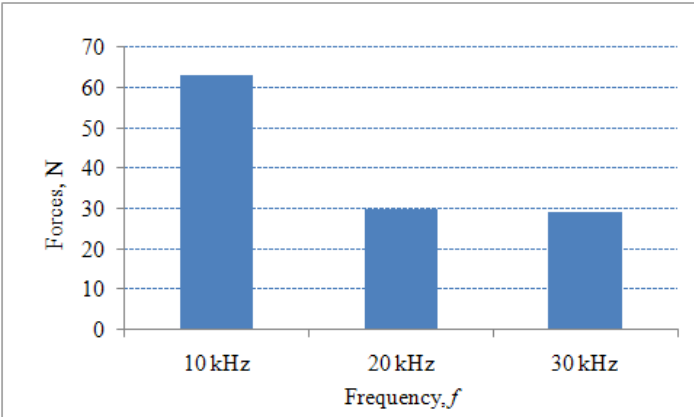

(a)

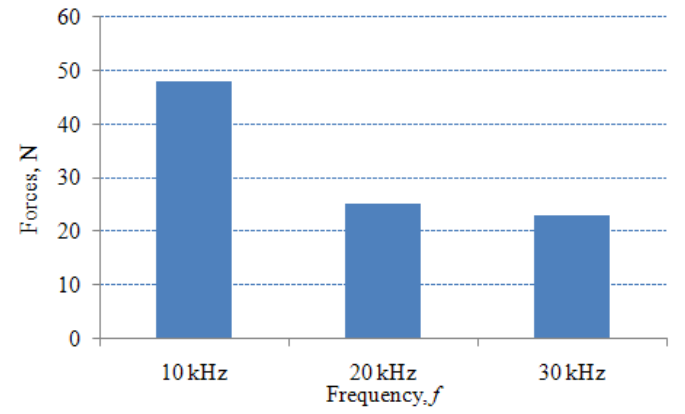

(b)

Figure 6: Effect of frequency on cutting forces (a) in UAT (b) in HUAT, at ( $a=30 \mu \mathrm{m})$

\section{Conclusion}

Computational and experimental methods were used to analyse the cutting forces in ultrasonically assisted turning, hot ultrasonically assisted turning and conventional turning. A 3D thermomechanically coupled finite element model for UAT, HUAT and CT of Ti-based super alloy is studied. The comparative study of three processes revealed many advantages of UAT and HUAT when compared to CT.

The cutting force reduces significantly with the application of ultrasonic vibration on the cutting tool. The HUAT of Ti-alloy reduces the further reduces the cutting forces when compared to UAT. The effect of vibration frequency and amplitude of vibration on the cutting forces is also 
investigated to suggest the optimum vibration parameter for UAT and HUAT. The cutting forces significantly increases with the decrease of vibration frequency form the selected experimental cutting condition and a small decrease in cutting forces was observed with the increase of frequency from $20 \mathrm{kHz}$ to $30 \mathrm{kHz}$. Similarly, the cutting forces increase considerably with a decrease of vibration amplitude form the selected experimental cutting condition. A noticeable decline in the cutting forces was observed with the increase of amplitude from $20 \mu \mathrm{m}$ to $30 \mu \mathrm{m}$.

\section{Acknowledgement}

The research leading to these results has received funding from the European Union Seventh Framework Programme (FP7/2007-2013) under grant agreement No. PITN-GA-2008211536, project MaMiNa.

Authors would also like to acknowledge Tampere University of Technology, Finland for providing material data of Ti-alloy.

\section{References:}

[1] N. Ahmed, A.V, Mitrofanov, V.I. Babitsky, V.V. Silberschmidt: Stresses in ultrasonically assisted turning. Applied Mechanics \& Materials 2006, 5-6:351-358.

[2] N. Ahmed, A.V, Mitrofanov, V.I. Babitsky, V.V. Silberschmidt: 3D finite element analysis of ultrasonically assisted turning. Computational Materials Science 2007, 39:149-154.

[3] N. Ahmed, A.V, Mitrofanov, V.I. Babitsky, V.V. Silberschmidt: Analysis of forces in ultrasonically assisted turning. Journal of Sound and Vibration 2007, 308:845-854.

[4] A.V. Mitrofanov, V.I, Babitsky, V.V. Silberschmidt: Thermomechanical finite element simulations of ultrasonically assisted turning. Computational Materials Science 2005, 32:463-471.

[5] N. Ahmed, A.V, Mitrofanov, V.I. Babitsky, V.V. Silberschmidt: Effect of lubrication and cutting parameters on ultrasonically assisted turning of inconnel 718. Materail Processing Technology 2005, 162-163:649-654.

[6] MSC.Marc User's Guide Version 2010. MSC Software Corporation LA. In.

[7] Z. Li, J, Lambros: Determination of the dynamic response of brittle composites by the use of the split Hopkinson pressure bar. Computational Science Technology 1999, 59:1097-1107.

[8] M. Demiral, A, Roy, V.V. Silberschmidt: Effects of loading conditions on deformation process in indentation. Computational Materials and Continua 2010 (Submitted).

[9] M. Baker, J, Rosler, C. Siemers: A finite element model of high speed metal cutting with adiabatic shearing. Computers \& Structures 2002, 80:495-513.

[10] H. Fassi, L, Bousschine, A. chaaba, A. Elharif: Numerical simulation of orthagonal cutting by incremental elsto-plastic analysis and finite element methods. Material Processing Technology 2003, 141:181-188.

[11] G. Shi, X, Deng, C. Shet: A finite element study of the effect of friction in orthogonal metal cutting. Finite Elements in Analysis \& Design 2002, 38:863-883. 